\title{
new technologies in global societies
}


This page is intentionally left blank 


\title{
new technologies in global societies
}

\author{
editors \\ pui-lam law \\ The Hong Kong Polytechnic University, China
}

leopoldina fortunati

University of Udine, Italy

shanhua yang

Peking University, China 


\title{
Published by
}

World Scientific Publishing Co. Pte. Ltd.

5 Toh Tuck Link, Singapore 596224

USA office: 27 Warren Street, Suite 401-402, Hackensack, NJ 07601

UK office: 57 Shelton Street, Covent Garden, London WC2H 9HE

\author{
Library of Congress Cataloging-in-Publication Data \\ New technologies in global societies / edited by Pui-Lam Law, Leopoldina Fortunati \& \\ Shanhua Yang. \\ p. $\mathrm{cm}$. \\ Includes bibliographical references and index. \\ ISBN 981-256-812-3 \\ 1. Technological innovations. 2. Technology. 3. Globalization. I. Luo, Peilin. \\ II. Fortunati, Leopoldina. III. Yang, Shanhua.
}

T173.8.N4772006

303.48'3--dc22

2006044632

\section{British Library Cataloguing-in-Publication Data}

A catalogue record for this book is available from the British Library.

Copyright $\odot 2006$ by World Scientific Publishing Co. Pte. Ltd.

All rights reserved. This book, or parts thereof, may not be reproduced in any form or by any means, electronic or mechanical, including photocopying, recording or any information storage and retrieval system now known or to be invented, without written permission from the Publisher.

For photocopying of material in this volume, please pay a copying fee through the Copyright Clearance Center, Inc., 222 Rosewood Drive, Danvers, MA 01923, USA. In this case permission to photocopy is not required from the publisher.

Typeset by Stallion Press

Email: enquiries@stallionpress.com 


\section{Acknowledgments}

Most of the papers in this collection emerged from the session on "The co-construction of society and technology in a global world," at the 36th World Congress of the International Institute of Sociology held in Beijing on July 7-12, 2004. We would like to thank the authors for their relentless commitment and their contributions to this collection. We would also like to express our gratitude to the reviewers for their thoughtful and meticulous comments. Finally, our thanks go to the Department of Applied Social Sciences of The Hong Kong Polytechnic University for their support of the publication of this book. 
This page is intentionally left blank 


\section{Introduction}

\section{Pui-lam Law, Leopoldina Fortunati and Shanhua Yang}

Technological advancements since the last millennium in the West have contributed to global modernity. They have led to the development of global connectivity (Wellman et al. 2005), mobility, and communication, and in turn, have occasioned globalization (Tomlinson 1999). Aviation technology has shrunk global spatial distance with the result that international mobility is more convenient and countries that are thousands of miles apart can now be reached in just a number of hours. Thus, air travel has been conducive to global closeness. The development of print, radio, television, the telephone, and the Internet have made global communication possible and people now have more access to the world (Barnett et al. 2003). Through these communication technologies people are able to instantly understand what is happening in other countries. For example the news of the July 7th, 2005 bombings in London was immediately transmitted all over the world and people had real time knowledge of what had happened. In addition, people are no longer restricted to body-to-body interactions within their own localities; they are able to connect with people from different localities throughout the world by fixed line or mobile phones or the Internet (Nyiri 2005).

Through the process of globalization the local is inevitably connected with the global, and the mix of global and local has restructured the social lives of the locals (Strassoldo 1992). For instance, an increase of just $2 \%$ on the average exchange rate between the Chinese yuan and the U.S. dollars has led to the closing of several small factories in a township in the southern part of China and in turn influenced the lives of migrant workers there, with family members in other parts of China being affected accordingly. People have started to be aware of the fact that when they make plans for their future knowledge of the local is insufficient without information of the global. Social relations have become more global as they have been influenced by processes or events that have taken place at a distance. Thus, some have argued that the 
local will in time be displaced by the global and consequently a global culture will be generated (Appadurai 1997).

Despite the fact that nation-states are globally connected, the emergence of a global culture is highly unlikely. It is widely believed that global modernity is indeed Western modernity, and that the powerful force of Western modernity is the sweeping expansion of its market economy (Sen 1999; Appadurai 1990). With the advancement of technology which makes connectivity and mobility among people of different nation-states more efficient and effective, the market economy has expanded its influence all over the world (Braman 1990). Yet Latouche (1996) clearly points out that the expansion of the Western style market economy, powerful though its impact is, is not able to uproot the different cultures of the so-called third world. Thus, it is an untenable belief that the adoption of a market economy will bring about the changes at social and cultural levels in the third world or non-Western societies. The development of the market economy in the West indeed has its own historical, social and cultural contexts which are different from non-Western societies (Gray 1997; Taylor 1999; Wallestein 1974). On the contrary, without the respective cultural elements of Western societies, a market economy can barely root itself in a proper fashion in non-Western soil. Indeed, economics in the East are specifically Asian in style.

The cultures of non-Western countries in fact have their own countervailing forces that counteract the power of the global economy. Thus this suggests that the powerful disembedding force of the global market economy can hardly generate a global culture, let alone a global society. It is widely agreed that the nation-states are well connected and consequently globalized, but the dialectical process of the global and local generates global societies.

The inherent connectedness of the social, cultural, political, and economic systems of society which give rise to the dialectical process of the global and local also illuminates an understanding of science and technology and their relationship with global societies. Science and technology have rapidly developed over the past three centuries in Western countries. Science has also presented itself in the form of universal knowledge. Ostensibly, science is in itself an autonomous intellectual enterprise aimed at understanding nature. Yet the flourishing of science in the West is intrinsically related to the socio-cultural changes that took place during the age of Enlightenment; and technology, the instrumental application of science, is without doubt inextricably linked to social needs (Maldonado 2005; Longo 2002). The shift in the technological paradigm is therefore, imputed more to changes in social needs and less to the result of the rational discussion of the autonomous scientific community. 
Taking the social nature of science and technology into account in order to understand their effects on global societies is essential. It is evident that science and technology are globally oriented and that their rapid development have resulted in global modernity. Technologies set conditions for the closeness of the nation-states and for the affinity of the global and the local. They are also penetrating everyday life, and even sometimes the body, producing radical social changes. For instance, Chen in this volume (Chapter 9) demonstrates that Internet use, which enables Chinese immigrants to Canada to engage in transnational entrepreneurship, shows the positive function of new technology. Yet, arguing that new technologies bring new life and a promising future to global societies remains a questionable thesis. For example, Pertierra (Chapter 2) succinctly points out that various aspects of everyday culture in Philippine society inhibit an orientation to science and that their undeveloped economy is unable to sustain high-level skills in technology. All these would prevent a scientific ethos from establishing local roots in the Philippines. In addition, Law and Peng (Chapter 11) maintain that, although the mobile phone is a new personalized communications device, its use among migrant workers in southern China, is one of the factors which revitalizes traditional kinship networks instead of bringing about a more individual lifestyle. More negatively, Liu and Lau (Chapter 12) have demonstrated that the Internet, which serves as an advertisement tool for the sex trade, has occasioned a new form of domination of sex workers through cyberspace.

This collection attempts to explore the relationship between new technologies and global societies, to gain an understanding of how the positive as well as negative influences of technologies bear on global societies, how their practices of use are resisted or re-interpreted by them, and how their social meaning is constituted through the process of negotiation with these societies. Part 1 is on science, technology, culture, and the body; Part 2 on new media and generations; and Part 3 on information and communication technologies (ICTs) and work.

\section{Part 1 Technology, Science, Culture, and the Body}

In Chapter 1, Pertierra discusses the cultural factors of everyday life that affect the development, practice and valuation of science in Philippine society. Despite various aspects that should encourage the development of science, such as widespread educational opportunities, an orientation towards Western modernity and the establishment of scientific institutions early in the American period, science in the Philippines has not generally prospered. Pertierra 
maintains that there are complex reasons for this relative lack of scientific development among which are a weak economy and a political system that neglects investments in long-term projects such as science education. There are also cultural elements of everyday life that prevent the development of a scientific ethos, such as the weak development of the public sphere, an undervaluing of specialized skills and an animated view of nature.

Prior work on university-industry relations has mostly focused on developed countries such as the United States, Japan and the countries of Western Europe, examining the shift in science policy from curiosity-driven research (Mode 1) to user-driven research (Mode 2). Little research has been done in China, where a Mode 2 -oriented policy has been persistently advocated since the 1950s. In the second chapter, Hong describes various forms of technology transfer from Chinese universities to industry that she identified through 40 in-depth interviews with university scientists and technology transfer officers in China. While a negative impact of commercial behavior on scientific research was found in low-level university-industry collaborations, scientists involved in higher-level industry-related research benefited from enhanced communication with colleagues. In contrast with the extensive interaction between applied research and development, the connection between basic and applied research is quite weak in China. Hong warns that, although basic research is not confined by a country's borders, knowledge transfer is. Moreover, low absorptive capacity due to underinvestment in basic science will preclude China from sharing the most advanced scientific knowledge. A Mode 2 -oriented science policy, though seemingly practical in the short run, will impair China's long-term international competitiveness.

There has long been discussion on the artificialization of the human body (Katz 2002; Fortunati 2002). People are increasingly confronted with new technologies getting closer to the human body, and the penetration of the latter by the former. The aim of this research was to monitor how the human body and new technologies, mainly the mobile and the Internet are perceived in this critical phase termed "mass prosthetization." By utilizing a social representations approach (Moscovici 1961/76; Jodelet 1989) as their framework, Contarello and Fortunati, in Chapter 3, explore the forms of social co-construction of the "technological" body being worked out in daily life. Their chapter is based on a study which explored symbolic and emotional levels relating to the human body, mobiles and the Internet, and analyzed bodily experience and attitudes towards mobiles and the Internet, gathered information on practices relative to these technologies, and finally examined opinions on the social impact of these on the human body. More than 200 Italian 
university students were interviewed and data was analyzed both through qualitative and quantitative procedures. In their chapter Contarello and Fortunati indicate that there were no straightforward rejections, nor great enthusiasm concerning the invasion of the body by machines, though a clear opposition between the human body and technology is emerging. In addition, a positive attitude towards technologies is confirmed, although with some concern. The Internet is perceived as having a twofold nature: work and play, hot and cold, science and chaos. Mobiles are associated with a rising "price-to-be-paid."

Technology can only develop within a social system. If one imagines a global world, technological development would be quite similar in all countries. The example of Preimplantation Genetic Diagnostics (PGD) shows that the German government chooses not to allow this technology, while it is legal in most other European countries. Wüstner in Chapter 4 analyzes why this is the case, and shows how the discourse about PGD in Germany can be described. In order to investigate it, Wüstner carried out a content analysis of several German newspapers and magazines and elaborated typical lines of argument. The content analysis focused on how processes of social construction can be reconstructed and how communication and legitimation processes of the structure and pattern of sense can be explained. The analysis presented in Chapter 4 results in the supposition that it is not the society that decides whether PGD is allowed or forbidden but that there are relevant social subsystems that are of importance in this respect. She further concludes that, although the relationship between technology and society is co-constructed, understanding how technology is socially represented within different social systems is also important as this is a crucial element of social thinking.

\section{Part 2 New Media and Generations}

With the increasing popularity of the Internet around the globe, newsgroup communication has acquired great significance as a source of documentation in social research. Yet the scanning of the contents of messages is difficult to perform within traditional reading and classification techniques, because of the huge amount of information and "background noise" (irrelevant elements) that interfere with the selection of significant "markers." Chapter 5 is a research report which aims to probe the potentiality of the technique called "the automatic analysis of textual data" (textual mining), in order to scan the content of newsgroups' messages. The objective is to minimize the loss of information on one hand, and to increase the meaningfulness of thematic inspection on the other, to serve as the possible starting point for a qualitative 
analysis. Research was carried out by Giuliano on eight Usenet Italian newsgroups from March 18 to April 18, 2005, during the Iraq war. The corpus of the research was made up of 35,492 messages, out of a total of $5,220,932$ occurrences. Two text-mining software programs were used: TALTAC, for the normalization, grammar tagging, and stemming of the Italian language; and SPAD-T 1.5/SPAD 5.0 for the multivariate analysis of textual data. The results confirm the overall performance potentiality of the strategy used in the selection of key words that properly describe the contents of messages. The results of the research show that in the newsgroups that were examined, there was general opposition to the war; however, different reasons were given and different viewpoints expressed. As a caveat, we must consider that it is not always possible to identify the ideological orientation of newsgroups because users seek to engage in debate and polcmical confrontations, and may also express thoughts that go beyond their own political beliefs.

With the tremendous information flow through new communication technologies which is supposed to influence people's ideological orientation, such as attitudes towards the Iraq war, Fortunati and Strassoldo in Chapter 6 investigate how the process of negotiation between societies and information technologies has been evolving in the global world, producing important changes in the organization of everyday life as well as in the widespread production of attitudes and opinions towards relevant social themes. They focus in particular on exploring relations between ICTs and youth in the age of globalization in Italy. They explore on one hand the use and quantity of use of ICTs, like TV, computers, and the use of more classical cultural instruments, like books and magazines, among youths of both genders and on the other hand, the diffusion and degree of diffusion of modalities of communicative sociality, with the aim of verifying if and on what terms ICT use correlates with practices of communicative sociality. Secondly they investigate how these youths see socio-political themes like one's own country, peace, war, terrorism, military service, and how they judged the events of Genoa where anti-globalization protesters clashed with police during a G8 meeting. In this chapter they also try to verify if and how the attitudes of youths towards all these themes correlate with their use of ICTs and their modes of communicative sociality. This analysis is particularly important for verification of the hypothesis that the existence of a media regime in Italy, undeniably controlled by the premier Berlusconi, has a strong conditioning effect on public opinion, and particularly youth opinion. Their analysis is based on a representative sample of Italian youth, interviewed by means of a questionnaire conducted face to face in June 2002. The data was analyzed by means of multivariate analysis methods. 
Research into teenagers and mobile phone use reveals that parents purchase their teenage children mobile phones to keep tabs on them and monitor their movements; another form of what Rakow and Navarro (1993) have dubbed "remote mothering." Sciriha in Chapter 7 discusses the results of a large-scale survey on mobile telephony, conducted in November 2003 among a scientifically representative sample of 500 respondents in Malta, a small island in the center of the Mediterranean. The survey sought to answer a number of questions including; when compared to Maltese in the older age groups, what role do teenagers play in the high penetration levels of mobile phones? What reasons do they give for phoning on mobiles rather than on fixed lines, even though mobile phone rates are very expensive compared with fixed lines? How long are teenagers willing to wait for answers to their urgent and/or not so urgent SMS messages? Do they lie when they are asked "Where are you?" From the results of the survey, Sciriha found that teenagers are the most enthusiastic users of mobile phones, and that mobile phones provide them with an earlier-than-anticipated independence from their parents. Although mobiles have provided parents with a new means of caring for their young, the sense of being able to be in immediate contact can be real and unreal. According to the data teenagers lie to their parents when contacted on their mobiles. She further maintains from her findings that telephones, especially mobile phones afford privacy to their users. They have also contributed to giving people a sense of freedom when in reality they have managed to enslave them. Once introduced, they cannot be ignored and the demand for them is still on the increase.

Mobile phones have also provided a new means for caring for the aged. Wong in Chapter 8 explores the use of mobile phones among residents of care homes for the elderly. This chapter examines the family relationships and communication patterns between residents of care homes and their family members with regard to the use of mobile phones. Wong introduces his research by observing that the changing structure of Hong Kong society has had an impact on the structure of the family. Families are shrinking in size, and if support networks for the elderly are available, they tend to be limited, which explains the development of care homes for the elderly. Data for the research was collected from a survey based on two sets of interview schedules. Mobile phone users who were resident in care homes were interviewed, and information on the home's regulations on the use of mobile phones was also collected from the home management. According to the findings, there are more male mobile phone users than female users, and women are slightly more likely than men to be daily users. The use of mobile phones is more about safety and security with some of the respondents stating that they feel 
better when they use their mobile phones. Wong concludes that the mobile phone is able to create a "cyber space" between the generations and that it promotes family resilience since spoken words of care count.

\section{Part 3 ICTs and Work}

At the intersection of the two literatures - immigration transnationalism and the interaction of technology and society - the role of Internet use with regard to transnational entrepreneurship provides a unique vantage point from which to observe the ways in which social, cultural, and technological forces affect economic actions. The impact of the Internet on transnationalism is frequently mentioned yet rarely researched. In Chapter 9 Chen attempts to explore the socio-technological dimension of transnational entrepreneurship by examining how Chinese immigrants to Canada rely on communication and social networks to engage in transnational entrepreneurship. Participant observations and in-depth interviews conducted in Toronto and Beijing indicate that Internet use has positive effects on transnational entrepreneurship in terms of searching for information, building and cultivating border-crossing social networks, and mobilizing important resources. However, the Internet is not everything, as transnational entrepreneurs selectively use multiple forms of communication media, depending on which is most convenient and socially appropriate.

In Chapter 10 Chu and Yang try to depict the push-pull factor between ICTs as signifiers of the age of globalization on the one hand, and the reinforcement and/or distortion of cultural factors for contemporary Chinese on the other. By means of intensive case studies on young peasant migrant workers working in townships in a South China village, the two researchers were able to examine the impact of social changes on the normative basis of this group of people. Chu and Yang tried to comprehend how their respondents perceived interpersonal relationships, re-interpreted kinship ties when distance was an issue, and how they interpreted the relationship between the individual and society with reference to their experience of living in a global era. By studying their patterns of mobile phone use, including text messaging, the duration of conversations, the selection of user packages, and the criteria for choosing phone models, the researchers were able to articulate what had and had not changed about peasant identity vis-à-vis Chinese cultural expectations, and the possible societal transformation within rural China.

Law and Peng in Chapter 11 echo the observations made by Chu and Yang by describing mobile phone consumption patterns of migrant workers and how mobile phones affect their social relationships. Law and Peng 
maintain that mobiles provide conditions for the displacement of traditions. Their interviews have shown that migrant workers are able to develop virtual connections with strangers and are able to join virtual networks through their mobile phones since these kinds of cyber relationships have the potential to provide a release from the problems of the real world. Yet unfavorable social conditions of the host society have also re-anchored them to networks within their places of origin. The mobile phone has made it possible for workers to reconnect either in person or through cyberspace, with their kinsmen or fellow villagers who are scattered far and wide throughout Guangdong, or even in other provinces. Wherever these kinsmen and villagers are, traditional village norms exist in the form of a floating cyber network (Gergen 2002, 2003) that exercises constraints on them when they are connected by mobile phone, either by SMS or by phone calls. Interestingly enough, the mobile, as a new kind of communication technology, has re-embedded migrant workers within the bosom of tradition.

Sex work is one of the oldest forms of work in human societies and one of the most crucial problems at both the social and political level (Fortunati 1981, Amer. Trans. 1995). The phenomenal development of information technology over the past decade, however, has affected this work in a new way, altering the conventional mode of disseminating sex information. In Chapter $12 \mathrm{Liu}$ and Lau set out to investigate how the proliferation of sex service information in Hong Kong, particularly concerning "one-woman brothels," is affected by the Internet. They do so by examining the contents of relevant websites identified via the search engines Google and Yahoo, as well as those under other relevant local web directories. The focus of the chapter is on the kinds of information available on sex services, on how this information is presented, and on how far this mode of information differs from that of conventional media like advertisements in newspapers and magazines. By examining these issues, Liu and Lau try to clearly depict the mode of presentation of sex service information on the web, showing that the power of sex workers is diminishing because of the further level of control and conditioning represented by the technical management of their access to the Internet.

\section{References}

Appadurai, A. 1990. "Disjuncture and Difference in the Global Cultural Economy." In Global Culture: Nationalism, Globalization and Modernity, edited by M. Featherstone. London: Sage.

Appadurai, A. 1997. Modernity at Large: Cultural Dimensions of Globalization. New Delhi: Oxford University Press. 
Barnett, M., S. Jarvenpaa and L. Silva. 2003. "ICTs, Globalization and Local Diversity." Communications of the Association for Information Systems 11 , available at http://cais.isworld.org/articles/11-27/default.asp?Vicw=pdf\& $\mathrm{x}=51$ \&y=10.

Braman, S. 1990. "Trade and Information Policy." Media, Culture $\mathfrak{O}$ Society 12:361-385.

Fortunati, L. 1981. L'arcano della Riproduzione. Venezia: Marsilio (Amer. Trans. The Arcane of Reproduction. New York: Autonomedia, 1995).

Gergen, K. J. 2002. "The Challenge of Absent Presence." In Perpetual Contact: Mobile Communication, Private Talk, Public Performance, edited by J. Katz and M. Aakhus. Cambridge: Cambridge University Press.

Gergen, K. J. 2003. "Self and Community in the New FloatingWorlds." In Mobile Democracy. Essays on Society, Selfand Politics, edited by K. Nyiri. Vienna: Passagen.

Gray, J. 1997. Endgames: Questions in Late Modern Political Thought. London: Polity Press.

Jodelet, D. 1989. Les représentations sociales. Paris: P.U.F.

Latouche, S. 1996. The Westernization of the World: The Significance, Scope and Limits of the Drive towards Global Uniformity. London: Polity Press.

Longo, G. O. 2002. "Mente e Tecnologia." Pluriverso IV(4) and V(1):135-146.

Maldonado, T. 2005. Memoria e Conoscenza. Sulle Sorti del Sapere Nella Prospettiva Digitale. Milano: Feltrinelli.

Moscovici. S. 1961. La Psychanalyse, Son Image et Son Public. Paris: P.U.F.

Nyiri, K., ed. 2005. A Sense of Place. The Global and the Local in Mobile Communication. Wien: Passagen Verlag.

Rakow, L. and V. Navaro. 1993. "Remote Mothering and the Parallel Shift: Women Meet the Cellular Phone." Critical Studies in Mass Communication 10(2):144-157.

Sen, A. 1999. Development as Freedom. New York: Random House.

Strassoldo, R. 1992. "Globalism and Localism: Theoretical Reflexions and Some Evidence." In Globalization and Territorial Identities, edited by Z. Mlinar. Albershot: Avebury.

Taylor, P. J. 1999. Modernities: A Geobistorical Interpretation. Minneapolis: University of Minnesota Press.

Tomlinson, J. 1999. Globalization and Culture. Cambridge, UK: Polity Press.

Wallerstein, I. 1974. "The Rise and Future Demise of the World Capitalist System: Concepts for Comparative Analysis." Comparative Studies in Society and History 16:399-406.

Wellman, B. et al. 2005. "Connected Lives: The Project." In The Networked Neighborbood, edited by P. Purcell. Berlin: Springer. 


\section{Contents}

Acknowledgments $\quad \mathrm{v}$

Introduction vii

Part 1 Science, Technology, Culture, and the Body 1

1 Science and the Culture of Everyday Life in the Philippines 3 Raul Pertierra

2 Technology Transfers of Chinese Universities: Is Mode 2 Sufficient for a Developing Country? 21 Wei Hong

3 ICTs and the Human Body: A Social Representation Approach 51 Alberta Contarello and Leopoldina Fortunati

4 Technological Development and Society: The Discourse on PGD in Germany

Kerstin Wïstner

\section{Part 2 New Media and Generations}

5 Analysis of the Content of Newsgroup Messages:

Methodological and Technical Issues

Luca Giuliano

6 Practices in the Use of ICTs, Political Attitudes Among Youth, and the Italian Media System

Leopoldina Fortunati and Raimondo Strassoldo

7 Teenagers and Mobile Phones in Malta: A Sociolinguistic Profile

Lydia Sciriba

8 Mobile Phones, Aged Homes, and Family Relations in

Hong Kong Preliminary Observations

William Wai-lim Wong 
9 The Impact of Internet Use on Transnational Entrepreneurship: The Case of Chinese Immigrants to Canada

Wenhong Chen

10 Mobile Phones and New Migrant Workers in a South China Village: An Initial Analysis of the Interplay between the "Social" and the "Technological"

Wai-chi Chu and Shanhua Yang

11 The Use of Mobile Phones among Migrant Workers in Southern China

Pui-lam Law and Yinni Peng

12 Sexuality as Public Spectacle: The Transformation of Sex Information and Service in the Age of the Internet Garland Liu and Joel Lau

Notes on the Contributors

Index 